\title{
Optimization of KOH etching process for MEMS square diaphragm using response surface method
}

\author{
Norliana Yusof ${ }^{1}$, Badariah Bais ${ }^{2}$, Norhayati Soin ${ }^{3}$, Jumril Yunas ${ }^{4}$, Burhanuddin Yeop Majlis ${ }^{5}$ \\ 1,2,4,5 Institute of Microengineering and Nanoelectronics (IMEN), Universiti Kebangsaan Malaysia, Malaysia \\ ${ }^{2}$ Centre of Advanced Electronic and Communication Engineering (PAKET), \\ Faculty of Engineering and Built Environment, Universiti Kebangsaan Malaysia, Malaysia \\ ${ }^{3}$ Department of Electrical Engineering, Faculty of Engineering, University of Malaya, Malaysia \\ ${ }^{1}$ Faculty of Innovative Design and Technology, Universiti Sultan Zainal Abidin, Malaysia
}

\begin{tabular}{l} 
Article Info \\
\hline Article history: \\
Received Nov 12, 2018 \\
Revised Jan 13, 2019 \\
Accepted Jan 27, 2019 \\
\hline
\end{tabular}

\section{Keywords:}

Etching process optimization

$\mathrm{KOH}$ etching

MEMS square diaphragm

Response surface method

Wet etching

\begin{abstract}
Potassium hydroxide $(\mathrm{KOH})$ wet etching is widely used in realizing microelectromechanical systems (MEMS) diaphragm due to its low cost, safe and easy handling. However, a variety of etching parameters such as etchant concentration, temperature, mask size and etching time need to be optimized thoroughly in order to save the time and costs of the etching process. This paper presents the numerical study and optimization of $\mathrm{KOH}$ etching process parameters using the response surface method (RSM) to realize the desired shape and size of MEMS diaphragm. Face central composite design (FCC) of RSM was employed as the experimental design to analyze the result and generate a mathematical prediction model. From the analysis, the temperature was identified as the most significant process parameter that affects the etching rate, thus affecting the thickness and size of the diaphragm. The results of RSM prediction for optimization were applied in this study. Particularly, $45 \%$ of $\mathrm{KOH}$ concentration, temperature of $80^{\circ} \mathrm{C}$, $1735 \mu \mathrm{m} 2$ of mask size, and 7.2 hours of etching time were implemented to obtain a square MEMS diaphragm with thickness of $120 \mu \mathrm{m}$ and size of 1200 $\mu \mathrm{m} 2$. The results of RSM based optimization method for $\mathrm{KOH}$ wet etching offers a quick and effective method for realizing a desired MEMS devices.
\end{abstract}

Copyright $\odot 2019$ Institute of Advanced Engineering and Science. All rights reserved.

\section{Corresponding Author:}

Badariah Bais,

Centre of Advanced Electronic and Communication Engineering (PAKET),

Faculty of Engineering and Built Environment,

Universiti Kebangsaan Malaysia,

43600 Bangi, Selangor, Malaysia.

Email: badariah@ukm.edu.my

\section{INTRODUCTION}

Wet etching has been extensively used for the fabrication of microelectromechanical systems (MEMS) components including diaphragms based on single crystal silicon due to its cost effectiveness, simple experiment setup, and easy handling compared to dry etching [1]. Even though potassium hydroxide $(\mathrm{KOH})$ and tetramethylammonium hydroxide (TMAH) are well known etchants used in wet etching process, $\mathrm{KOH}$ is more commonly used due to its high anisotropy reaction between the $\mathrm{Si}\{111\}$ and $\mathrm{Si}\{100\}$ planes [2]. Moreover, the etch rate of $\mathrm{Si}\{100\}$ is higher in KOH than in TMAH. Notably, this is indispensable for high productivity to reduce the cost of end products [3]. Nonetheless, the etching of (100)oriented silicon using aqueous $\mathrm{KOH}$ creates $\mathrm{V}$-shaped grooves problems with the (111) planes at an angle of $54.74^{\circ}$ from the (100) surface, as illustrated in Figure 1. From Figure 1, the etch depth, $d$, and the width of the opening, $W$, can be determined when (100) wafers are used: 


$$
W=L-2 a=L-\frac{2 d}{\tan 54.74^{\circ}}=L-\frac{2 d}{1.414}
$$

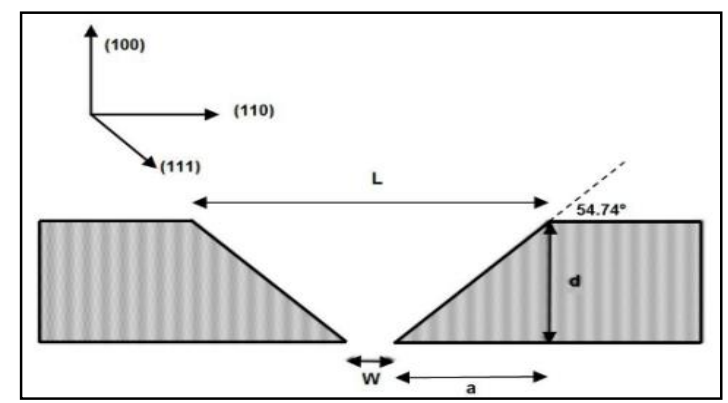

Figure 1. Formation of a V-shaped groove in (100) silicon using a $\mathrm{KOH}$ solution [4]

The etching characteristics of silicon wafers are vital for the fabrication of specific microstructural feature via wet etching technology. Even though the anisotropic etch characteristics of different types of wet etchants are well documented in the literature, the ideal condition for releasing a variety of complex, bulk micromachined structures are typically done using the trial-and-error method [5]. The classical onefactor-at-a-time (OFAT) method does not indicate the interactive effects of all parameters involved. Plus, it requires numerous experimental runs to attain the optimum levels and hence, consume too much time and has low cost effectiveness [6]. Many researchers had utilized statistically optimization in their research to conduct much more systematic approach [6]-[14]. One of the most well-known statistical design experiments is response surface method (RSM). RSM is a statistical technique to describe the behavior of set of data with the objective of making statistical previsions [9]. Generally, it is applied in statistical experimental design to determine the effect of factors, make prediction, search for optimum target, analyze interaction among variables, and propose a mathematical model that signify the whole process [10]. The major application of RSM is for optimization purposes. Therefore, the present study utilized the RSM method to investigate the characteristics of $\mathrm{KOH}$ wet etching with the aim to optimize the etching process parameters in realizing a simple square MEMS diaphragm. Four important parameters, namely temperature, KOH concentration, etching time, and mask size were investigated before designing the diaphragm. The interactions among the parameters were analyzed using the face central composite (FCC) experimental design.

\section{RESEARCH METHOD}

First and foremost, $\mathrm{KOH}$ wet etching simulation was conducted using AnisE, the etch simulation tool in IntelliSuite. Then, the output simulation values were statistically analyzed using RSM. Finally, the MEMS square diaphragm was fabricated to verify the reliability of the statistical model.

\subsection{Simulation of $\mathrm{KOH}$ Wet Etching using IntelliSuite Software}

Etch simulation tool of IntelliSuite, AnisE was used to generate the 3D model for anisotropic etching of silicon. With AnisE, the simulation of etching was conducted under various parameters of temperature, $\mathrm{KOH}$ concentration, etching time and mask size. Conducting etching simulation significantly reduced the fabrication cost and time. Most importantly, it help researchers to investigate etching behaviors, make prediction, and optimize the MEMS devices. Figure 2 shows the sample structure of MEMS square diaphragm simulated using AnisE.

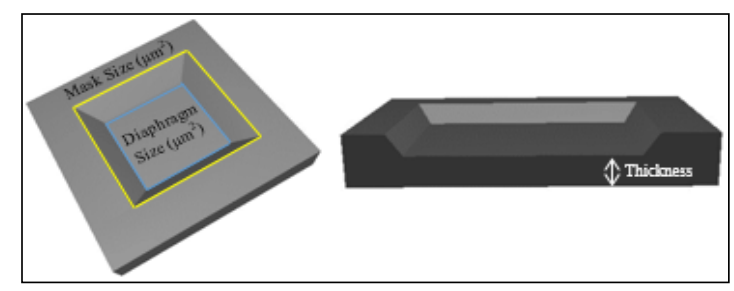

Figure 2. Model of MEMS square diaphragm 


\subsection{Statistical Analysis using Response Surface Method}

In order to investigate the $\mathrm{KOH}$ etching parameters, RSM using Design-Expert software was chosen as the statistical method. In this paper, the etching factor parameters, namely temperature, $\mathrm{KOH}$ concentration, etching time, and mask size for square MEMS diaphragm were selected to investigate their interaction to the output responses namely diaphragm's thickness, etch rate, and diaphragm's size. Table 1 presents the levels of etching parameters and the targeted output responses. The levels of each factor in the current research were selected based on previous related studies [4], [15-19]. The main target in the present study is to develop MEMS square diaphragm with size of $1200 \mu \mathrm{m} 2$ and thickness of $120 \mu \mathrm{m}$.

Table 1. Etching Factor Parameters and Output Response with Their Respective Codes

\begin{tabular}{cccccc}
\hline Code & Factor/ & Etching Parameters & $\begin{array}{c}\text { Low level } \\
(-1)\end{array}$ & $\begin{array}{c}\text { Center } \\
(0)\end{array}$ & $\begin{array}{c}\text { High Level } \\
(+1)\end{array}$ \\
\hline $\mathrm{A}$ & Fesponse & Temperature $\left({ }^{\circ} \mathrm{C}\right)$ & 40 & 60 & 80 \\
$\mathrm{~B}$ & Factor & KOH Concentration $(\%)$ & 25 & 37.5 & 50 \\
$\mathrm{C}$ & Factor & Etching Time $(\mathrm{h})$ & 1 & 3.35 & 5.7 \\
$\mathrm{D}$ & Factor & Mask Size $(\mu \mathrm{m} 2)$ & 1200 & 1600 & 2000 \\
$\mathrm{E}$ & Response & Diaphragm Thickness $(\mu \mathrm{m})$ & \multicolumn{3}{c}{ Target $=120 \mu \mathrm{m}$} \\
$\mathrm{F}$ & Response & Etch rate $(\mu \mathrm{m} / \mathrm{h})$ & \multicolumn{3}{c}{ Target $=$ Maximum $=1200 \mu \mathrm{m} 2$} \\
$\mathrm{G}$ & Response & Diaphragm Size $(\mu \mathrm{m} 2)$ & \multicolumn{3}{c}{} \\
\hline
\end{tabular}

\subsection{Fabrication of Square Diaphragm}

In this research, a $\langle 100\rangle$ oriented n-type silicon wafer of 4-inch diameter, $525 \pm 25 \mu \mathrm{m}$ thickness, with double-sided $200 \mathrm{~nm}$ coated silicon nitride was used. After dicing the wafer into $2.5 \mathrm{~cm} \times 2.5 \mathrm{~cm}$ size, the substrates were cleaned to remove any organic contaminants. The fabrication of square diaphragm utilized $\mathrm{KOH}$ wet etching with prior steps of photolithography and Buffered oxide etchant (BOE) etching process [15]. Before the photolithography process, the sample was spin coated with AZ 1500 positive photoresist using spin coater with a spin setting of $500 \mathrm{rpm}$ for $5 \mathrm{~s}$, followed by $3000 \mathrm{rpm}$ for $35 \mathrm{~s}$. Then, the resist was baked at $100^{\circ} \mathrm{C}$ for $1 \mathrm{~min}$. In order to transfer the pattern of square diaphragm to the sample, the sample was exposed to UV exposure for $35 \mathrm{~s}$. Next, the sample was baked at $100^{\circ} \mathrm{C}$ for $2 \mathrm{~min}$. Then, the pattern was developed by immersing the sample in AZ300K developer for $1 \mathrm{~min}$. In order to prepare the window pattern for the $\mathrm{KOH}$ wet etching, the silicon nitride layer was etched. BOE etching method was used to remove the nitride layer with the etching rate of $45 \mathrm{~nm} \mathrm{~min}-1$ at $80^{\circ} \mathrm{C}$ [20]. In this study, the sample was immersed in $\mathrm{BOE}$ solution by double boiling at constant $80^{\circ} \mathrm{C}$ temperature for $10 \mathrm{~min}$ to completely remove the $200 \mathrm{~nm}$ nitride layer on unprotected photoresist layer [15]. Finally, wet anisotropic etching was performed by double boiling process as shown in Figure 3. The double boiler heating method was preferred due to its controllability and its ability to provide consistent heating to the etchant [21].

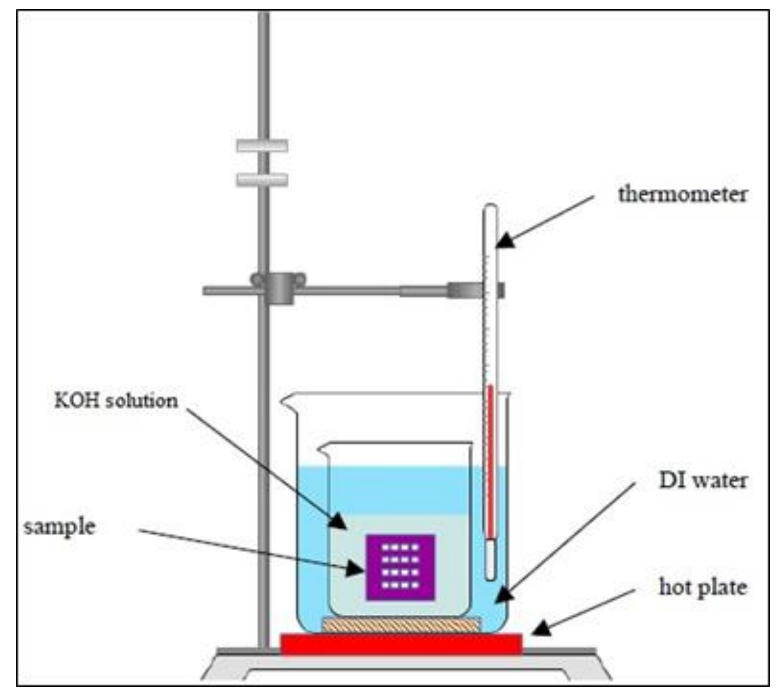

Figure 3. $\mathrm{KOH}$ etching process setup [11] 


\section{RESULT AND DISCUSSION}

This section presents the etching simulation results, statistical analysis and optimization using RSM, in addition to the comparison of RSM prediction with simulated and experimental etching results of fabricated MEMS square diaphragm.

\subsection{Etching Simulation Result by IntelliSuite}

First, the etching of square (100) silicon MEMS diaphragm was carried out over a range of etching parameters as shown in Table 1 using IntelliSuite, AnisE software. Next, the output responses obtained from the simulation were collected and tabulated as illustrated in Table 2.

Table 2. Experimental Design of KOH Etching Simulation

\begin{tabular}{|c|c|c|c|c|c|c|c|}
\hline Run\Code & A & $\mathrm{B}$ & $\mathrm{C}$ & $\mathrm{D}$ & $\mathrm{E}$ & $\mathrm{F}$ & $\mathrm{G}$ \\
\hline 1 & 0 & 0 & 0 & 0 & 436 & 21.175 & 1520 \\
\hline 2 & 0 & -1 & 0 & 0 & 421.5 & 25.98 & 1480 \\
\hline 3 & 0 & 0 & -1 & 0 & 494.2 & 21.175 & 1580 \\
\hline 4 & -1 & 1 & -1 & 0 & & 3.78 & \\
\hline 5 & 1 & 1 & 1 & -1 & 247 & 46.06 & 840 \\
\hline 6 & -1 & 1 & -1 & -1 & & 3.78 & \\
\hline 7 & 0 & 0 & 0 & 0 & 436 & 21.175 & 1520 \\
\hline 8 & 1 & -1 & -1 & -1 & 436 & 84.11 & 1100 \\
\hline 9 & -1 & -1 & -1 & -1 & & 6.91 & \\
\hline 10 & 1 & 0 & 0 & 0 & 276.2 & 68.555 & 1280 \\
\hline 11 & 1 & -1 & 1 & -1 & 14.5 & 84.11 & 520 \\
\hline 12 & -1 & 0 & 0 & 0 & 494.2 & 5.63 & 1580 \\
\hline 13 & 0 & 1 & 0 & 0 & 465.1 & 14.23 & 1540 \\
\hline 14 & -1 & 1 & 1 & -1 & 494.2 & 3.78 & 1180 \\
\hline 15 & 0 & 0 & 1 & 0 & 392.4 & 21.175 & 1440 \\
\hline 16 & -1 & -1 & 1 & -1 & 479.6 & 6.91 & 1160 \\
\hline 17 & 1 & 1 & -1 & 1 & 465 & 46.06 & 1940 \\
\hline 18 & -1 & -1 & 1 & 1 & 479.6 & 6.91 & 1960 \\
\hline 19 & 0 & 0 & 0 & 0 & 436 & 21.175 & 1520 \\
\hline 20 & 1 & -1 & 1 & 1 & 14.5 & 84.11 & 1320 \\
\hline 21 & 0 & 0 & 0 & 1 & 436 & 21.175 & 1900 \\
\hline 22 & -1 & -1 & -1 & 1 & & 6.91 & \\
\hline 23 & 0 & 0 & 0 & 0 & 436 & 21.175 & 1520 \\
\hline 24 & 0 & 0 & 0 & -1 & 436 & 21.175 & 1100 \\
\hline 25 & 0 & 0 & 0 & 0 & 436 & 21.175 & 1520 \\
\hline 26 & 1 & -1 & -1 & 1 & 436 & 84.11 & 1900 \\
\hline 27 & 1 & 1 & 1 & 1 & 247 & 46.06 & 1640 \\
\hline 28 & 1 & 1 & -1 & -1 & 465.1 & 46.06 & 1140 \\
\hline 29 & 0 & 0 & 0 & 0 & 436 & 21.175 & 1520 \\
\hline 30 & -1 & 1 & 1 & 1 & 494 & 3.78 & 1980 \\
\hline
\end{tabular}

*run number 4, 6, 9, and 22 were subjected to simulation constraints to measure diaphragm's thickness and size

\subsection{Statistical Analysis of Response Surface Method}

The process of statistical analysis was started with analysis of variance (ANOVA) in order to evaluate the adequacy of the response surface model developed. Table 3 shows the ANOVA for the data generated by the RSM model for KOH wet etching simulation. The $p$-value of $p<0.0001$ indicated that the model was significant. The value of R-squared (R2) describes up to what extent a model can perfectly estimate the experimental data points, whereas the adjusted R2 measures the amount of variation on the mean values explained by the model [22]. From Table 3, the predicted R2 values were close to the actual R2 values. This reveals that the experimental data fitted well with the predicted values of the model.

Table 3. Analysis of Variance (ANOVA)

\begin{tabular}{cccccc}
\hline Response & $\mathrm{p}$-value & $\mathrm{R} 2$ & Adjusted R2 & Predicted R2 & Mean \\
\hline Diaphragm Thickness & $<0.0001$ & 0.9959 & 0.9939 & 0.9831 & 396.31 \\
Etch rate & $<0.0001$ & 1.0000 & 1.0000 & 1.000 & 1.28 \\
Diaphragm Size & $<0.0001$ & 0.9988 & 0.9982 & 0.9953 & 1450 \\
\hline
\end{tabular}

The final regression models in terms of actual factors for diaphragm's thickness, etch rate, and diaphragm's size predictions are outlined as: 
Diaphragm Thickness $=590.29280+(10.51111 \square$ Temperature $)-(17.44854 \square \mathrm{KOH}$ Concentration $)+$ $(17.83930 \square$ Time $)-(5.35714 \times 10-5 \square$ Mask Size $)+(0.21363 \square$ Temperature $\square$ KOH Concentration $)-$ $(1.85479 \square$ Temperature $\square$ Time $)+(1.69434 \square \mathrm{KOH}$ Concentration $\square$ Time $)-(0.14128 \square$ Temperature 2$)$

$\log 10($ Etch Rate $)=-0.57981+(0.036901 \square$ Temperature $)+9.63770 \times 10-3 \square$ KOH Concentration + (4.62548x10-7 $\square$ Temperature $\square \mathrm{KOH}$ Concentration $)-(8.14864 \times 10-5 \square$ Temperature2) $-(2.6845 \times 10-4 \square$ KOH Concentration2)

Diaphragm Size $=31.72340+(17.47264 \square$ Temperature $)-(24.01191 \square$ KOH Concentration $)+(24.60993$ Time $)+(1.00000 \square$ Mask Size $)+(0.29400 \square$ Temperature $\square$ KOH Concentration $)-(2.55319$ Temperature $\square$ Time $)+(2.33191 \square \mathrm{KOH}$ concentration $\square$ Time $)-(0.21944 \square$ Temperature 2$)$

The relative differences among the parameters are illustrated through perturbation plots in Figure 4, Figure 5, and Figure 6 to provide notable summary for the responses. By default, the Design-Expert software sets the reference point at the midpoint (coded value 0 ) of all factors. The perturbation plot can be used to find the factors that affect the responses the most. Figure 4 shows the perturbation plot for the etch rate (100) and evidently, it was mainly influenced by temperature (A), with small influence from $\mathrm{KOH}$ concentration (B). Moreover, Factor A was directly proportional with the etch rate (100) and this was different for Factor B which was inversely proportional to the etch rate. Meanwhile, the etching time (C) and mask size (D) did not give any effect on the etch rate (100).

Figure 5 illustrates the perturbation plot for the diaphragm thickness. Notably, the etching temperature (A) and etching time (C) had the most significant effect on the diaphragm thickness. Thus, these two parameters should be well controlled to obtain a very thin diaphragm. In contrast, varying the $\mathrm{KOH}$ concentration (B) did not give significant effect on the thickness. This showed a positive correlation between the etch rate (100) and diaphragm thickness as the temperature increase would increase the etch rate (100), thus, decreasing the diaphragm's thickness.

Figure 6 portrays the perturbation plot for the diaphragm size. From Figure 6, the mask size (D) was found to be the most important parameter that should be controlled to realize the desired diaphragm size. Apart from that, temperature (A) and etching time (C) had small influences, whereas $\mathrm{KOH}$ concentration (B) had no statistical significance to the diaphragm size. Figure 7 shows the combined effect of KOH concentration and temperature on the etch rate (100). From Figure 7, KOH concentration did not affect the etch rate, but when combined with high temperature $\left(80^{\circ} \mathrm{C}\right)$, it would give significant effect to the etch rate. Referring to Figure 7, the etch rate increased with the rise of temperature, and it accelerated starting from $60^{\circ} \mathrm{C}$ to $80^{\circ} \mathrm{C}$.

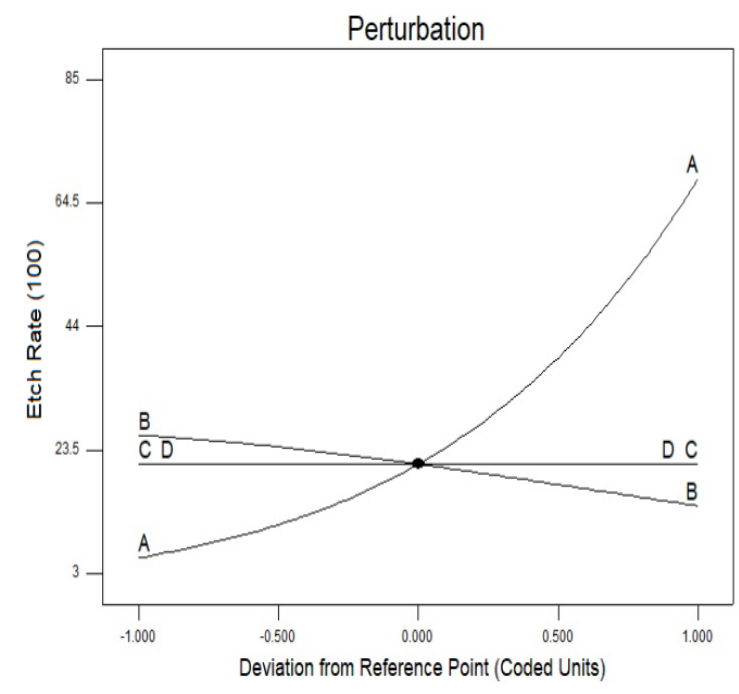

Figure 4. Perturbation plot for etch rate

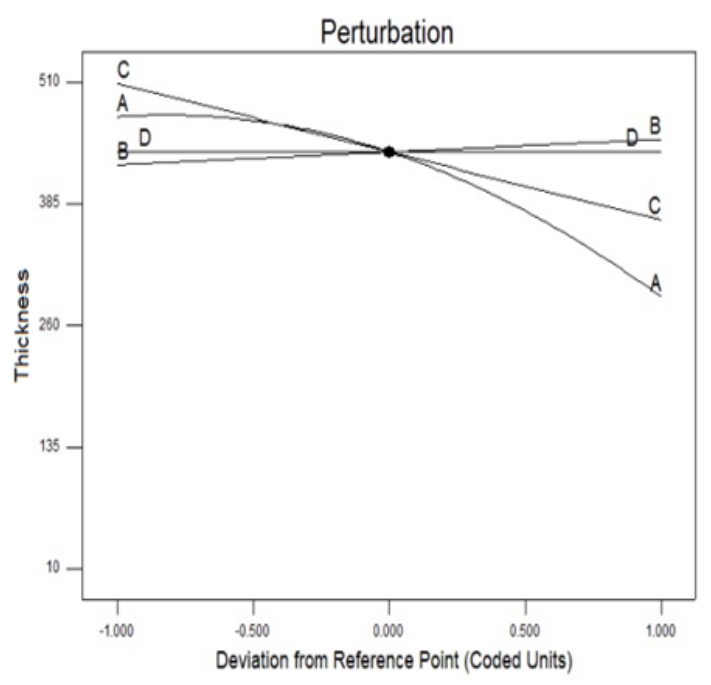

Figure 5. Perturbation plot for thickness 


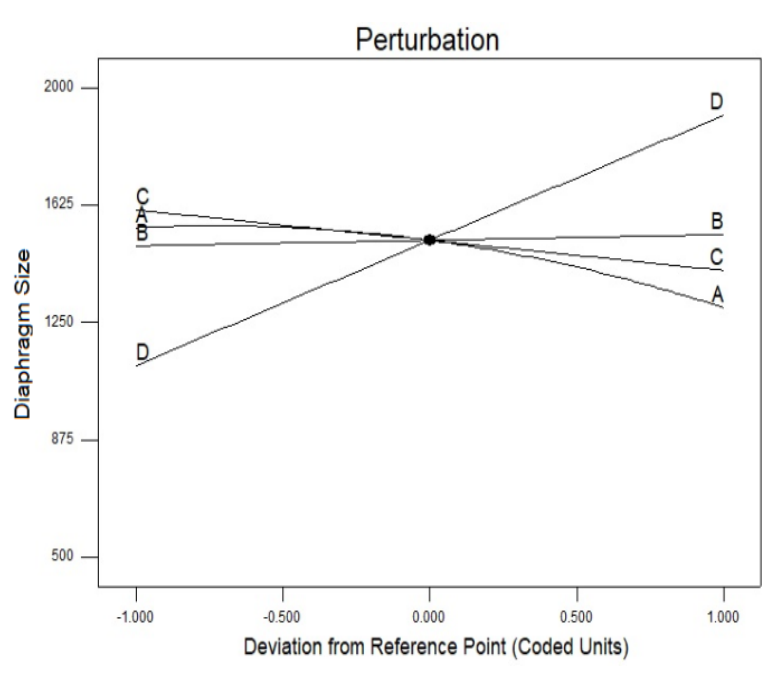

Figure 6. Perturbation plot for diaphragm's

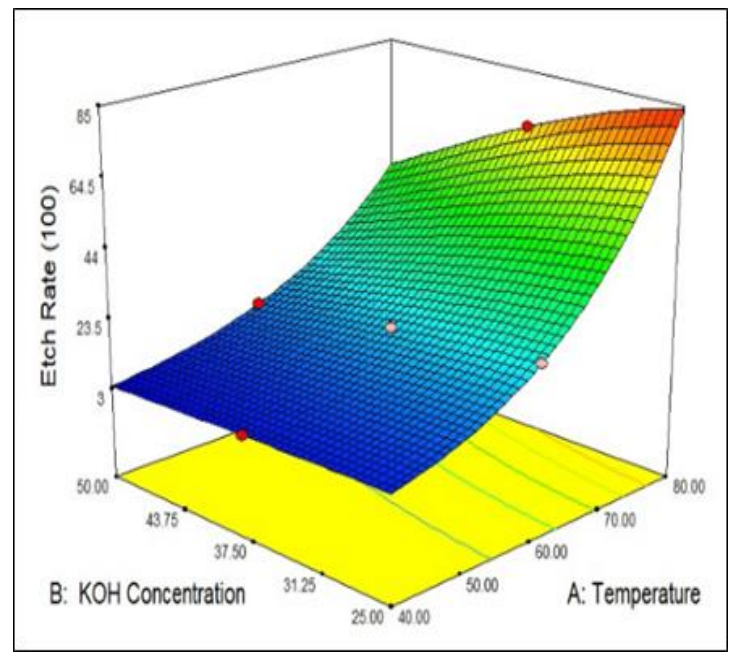

Figure 7. Combined effect of concentration and temperature on etch rate

\subsection{Optimization of MEMS Square Diaphragm Size}

The discussion depicts that all of the factors had a significant effect on the responses. Hence, all the factors should be set at optimum condition so the MEMS structure could be realized for desired thickness and size with minimum etching time. In this study, the goal for multi-objective optimization was to minimize the etching time with the targeted diaphragm's thickness of $120 \mu \mathrm{m}$ and targeted diaphragm's size of $1200 \mu \mathrm{m}^{2}$. In this optimization process, the $\mathrm{KOH}$ concentration was fixed at $45 \%$ in order to avoid rough surfaces of the silicon etched [11]. Even though low $\mathrm{KOH}$ concentration was better in achieving high etching rate (100), this parameter should be compensated with surface roughness parameter to get a smooth surface. Moreover, $\mathrm{KOH}$ concentration had less significant effect to the etching rate (100) if compared to the temperature. Table 4 shows the best four predicted values to achieve multi-objective optimization goals via the RSM model developed. The ideal technique for selecting the optimum operating characteristics of the etching process was by referring to the desirability approach. Higher desirability score of the resulting response reflects better optimization of the etching characteristics $[23,24]$. These results demonstrate that in order to obtain a desired optimization target, the controlled factors should be set approximately at temperature (A) $\approx$ $80^{\circ} \mathrm{C}$; $\mathrm{KOH}$ concentration $(\mathrm{B})=45 \%$; etching time $(\mathrm{C}) \approx 7.2 \mathrm{~h}$; with mask size $(\mathrm{D})=1735 \mu \mathrm{m}^{2}$. At this condition, the diaphragm's thickness $(\mathrm{E})$, etch rate $(\mathrm{F})$, and mask size $(\mathrm{G})$ were predicted to be approximately $120 \mu \mathrm{m}, 55 \mu \mathrm{m} / \mathrm{h}$, and $1200 \mu \mathrm{m}^{2}$, respectively. These controlled values were applied in IntelliSuite simulation and experimental etching process, and consecutively, compared with the RSM prediction.

Table 4. Optimal Etching Parameters for Targeted Diaphragm Structure

\begin{tabular}{ccccccccc}
\hline Run & $\begin{array}{c}\mathrm{A} \\
(\mathrm{OC})\end{array}$ & $\begin{array}{c}\mathrm{B} \\
(\%)\end{array}$ & $\begin{array}{c}\mathrm{C} \\
(\mathrm{h})\end{array}$ & $\begin{array}{c}\mathrm{D} \\
(\mathrm{um} 2)\end{array}$ & $\begin{array}{c}\mathrm{E} \\
(\mathrm{um})\end{array}$ & $\begin{array}{c}\mathrm{F} \\
(\mathrm{um} / \mathrm{h})\end{array}$ & $\begin{array}{c}\mathrm{G} \\
(\mathrm{um} 2)\end{array}$ & Desirability \\
\hline 1 & 80.0 & 45.0 & 7.19 & 1735 & 120 & 55.29 & 1200 & 0.96 \\
2 & 80.0 & 45.0 & 7.22 & 1735 & 120 & 55.04 & 1200 & 0.96 \\
3 & 80.0 & 44.9 & 7.18 & 1747 & 120 & 55.27 & 1212 & 0.96 \\
4 & 80.0 & 45.0 & 7.20 & 1756 & 120 & 55.27 & 1221 & 0.96 \\
\hline
\end{tabular}

\subsection{Comparison of Simulation and Experimental Etching Results}

The simulation and fabrication of MEMS square diaphragm were conducted by adopting the predicted parameters as estimated by RSM. Figure 8 shows the KOH etched square diaphragm by IntelliSuite simulation. The simulated results indicated that the thickness and size of the diaphragm were $102 \mu \mathrm{m}$ and $1240 \mu \mathrm{m}^{2}$, respectively. Figure 9 presents the experimental results of anisotropic etched silicon on a square diaphragm. From Figure 9, the diaphragm's size was shown to have a dimension of approximately $1275 \mu \mathrm{m}^{2}$, while the thickness of the diaphragm was approximately $120.2 \mu \mathrm{m}$. Table 5 shows the comparison of the diaphragm's size and thickness between the RSM prediction, simulation, and experimental results. For the simulated results, the diaphragm's size and thickness showed small dimensional deviation, with $15 \%$ thickness variation and $3.3 \%$ size variation. The comparison between the experimental and predicted results 
indicated that the error was $0.17 \%$ in terms of diaphragm's thickness and $6.25 \%$ for the diaphragm's size. In order for statistical analysis to be reliable, error values must be less than $20 \%$ [25]. Hence, from the results, it was concluded that the model developed using RSM could accurately predict the $\mathrm{KOH}$ etching process.

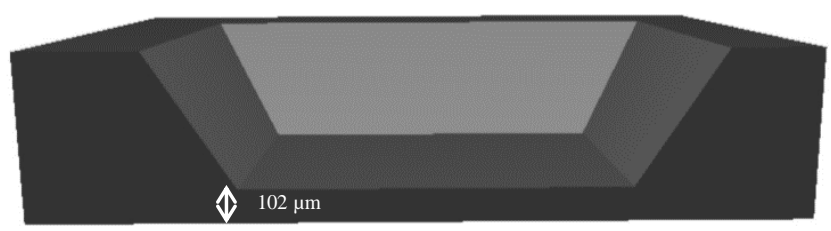

Figure 8. Simulated result of cross-sectional view of the MEMS square diaphragm structure

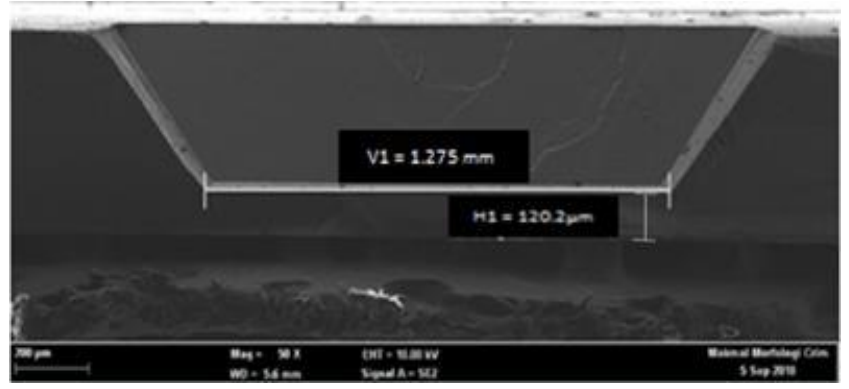

Figure 9. SEM picture of experimental results of anisotropic etched silicon on a square diaphragm

Table 5. Comparison of the Predicted Optimum Conditions

\begin{tabular}{|c|c|c|c|}
\hline Method & Diaphragm size & $\begin{array}{c}\text { Diaphragm } \\
\text { Thickness }\end{array}$ & $\begin{array}{l}\text { Deviation error with RSM } \\
\text { prediction }\end{array}$ \\
\hline RSM Prediction & $1200 \mu \mathrm{m} 2$ & $120.0 \mu \mathrm{m}$ & - \\
\hline $\begin{array}{l}\text { Intellisuite } \\
\text { Simulation }\end{array}$ & $1240 \mu \mathrm{m} 2$ & $102.0 \mu \mathrm{m}$ & $\begin{array}{c}15.0 \% \text { (diaphragm thickness) } \\
3.3 \% \text { (diaphragm size) }\end{array}$ \\
\hline $\begin{array}{l}\text { Experimental } \\
\text { KOH Etching }\end{array}$ & $1275 \mu \mathrm{m} 2$ & $120.2 \mu \mathrm{m}$ & $\begin{array}{c}0.17 \% \text { (diaphragm thickness) } \\
6.25 \% \text { (diaphragm size) }\end{array}$ \\
\hline
\end{tabular}

\section{CONCLUSION}

The implementation of RSM based design optimization for MEMS square diaphragm structure is presented. The mathematical models have been developed for silicon etch rate (100), thickness and size of the diaphragm. The statistical RSM results based on these mathematical models were satisfactory and in accordance with the results of the simulation and the experiment. The optimization results demonstrate that in order to obtain the square MEMS diaphragm with thickness of $120 \mu \mathrm{m}$ and size of $1200 \mu \mathrm{m} 2$, the controlled factors should be set approximately at etching temperature $\approx 80^{\circ} \mathrm{C} ; \mathrm{KOH}$ concentration $=45 \%$; etching time $\approx 7.2 \mathrm{~h}$; with mask size $=1735 \mu \mathrm{m} 2$. The difference between the validated value and the RSM predicted value was within $0.17-15 \%$, indicating that RSM method was able to predict the optimum parameters of $\mathrm{KOH}$ etching with low error. Hence, RSM was found to be an effective method to predict the wet etching process parameters for realizing MEMS structure, thus reducing the time consumed and the fabrication cost of refining those etching parameters.

\section{ACKNOWLEDGMENT}

The first author would like to thank Malaysia's Ministry of Higher Education (MOHE) and Universiti Sultan Zainal Abidin (UniSZA) for the financial support in the form of doctoral scholarship. The authors would also like to acknowledge the GUP-2017-031 grant for funding this project and the Centre for Research \& Instrumentation Management (CRIM), UKM for the FESEM analyses. 


\section{REFERENCES}

[1] P. Pal and K. Sato, "A comprehensive review on convex and concave corners in silicon bulk micromachining based on anisotropic wet chemical etching," Micro Nano Syst. Lett., vol. 3, no. 1, p. 6, 2015.

[2] H. Tanaka, S. Yamashita, Y. Abe, M. Shikida, and K. Sato, "Fast etching of silicon with a smooth surface in high temperature ranges near the boiling point of $\mathrm{KOH}$ solution," Sensors Actuators, A Phys., vol. 114, no. 2-3, pp. 516-520, 2004.

[3] Y. Xing, S. Haldar, K. Sato, A. Ashok, and P. Pal, "Anisotropic etching in low-concentration KOH: effects of surfactant concentration," Micro \&amp; Nano Lett., vol. 10, no. 4, pp. 224-228, 2015.

[4] M. Yun, "Investigation of KOH Anisotropic Etching for the Fabrication of Sharp Tips in Silicon-on-Insulator (SOI) Material," J. Korean Phys. Soc., vol. 37, no. 5, pp. 605-610, 2000.

[5] S. Dutta, M. Imran, P. Kumar, R. Pal, P. Datta, and R. Chatterjee, "Comparison of etch characteristics of KOH, TMAH and EDP for bulk micromachining of silicon (110)," Microsyst. Technol., vol. 17, no. 10-11, pp. 1621-1628, Sep. 2011.

[6] S. N. Selamat, M. I. E. Bin Halmi, S. R. S. Abdullah, M. Idris, H. A. Hasan, and N. Anuar, "Optimization of lead $(\mathrm{Pb})$ bioaccumulation in Melastoma malabathricum L. by response surface methodology (RSM)," Rend. Lincei, 2017.

[7] B. Mulyanti et al., "Modeling and optimization of fiber optic chemical vapor sensor," J. Telecommun. Electron. Comput. Eng., vol. 9, no. 2, pp. 73-79, 2017.

[8] H. Hazura et al., "Response surface approach to optical channel dropping filter design parameters optimization," J. Telecommun. Electron. Comput. Eng., vol. 10, no. 2-5, pp. 125-129, 2018.

[9] M. A. Bezerra, R. E. Santelli, E. P. Oliveira, L. S. Villar, and L. A. Escaleira, "Response surface methodology (RSM) as a tool for optimization in analytical chemistry," Talanta, vol. 76, no. 5, pp. 965-977, 2008.

[10] S. N. A. Sanusi, M. I. E. Halmi, S. R. S. Abdullah, H. A. Hassan, F. M. Hamzah, and M. Idris, "Comparative process optimization of pilot-scale total petroleum hydrocarbon (TPH) degradation by Paspalum scrobiculatum L. Hack using response surface methodology (RSM) and artificial neural networks (ANNs)," Ecol. Eng., vol. 97, pp. 524-534, 2016.

[11] R. M. Larik, M. W. Mustafa, and M. K. Panjwani, “A statistical jacobian application for power system optimization of voltage stability,” Indones. J. Electr. Eng. Comput. Sci., vol. 13, no. 1, pp. 331-338, 2019.

[12] S. D. Ashrafi, H. Kamani, J. Jaafari, and A. H. Mahvi, "Experimental design and response surface modeling for optimization of fluoroquinolone removal from aqueous solution by $\mathrm{NaOH}$-modified rice husk," Desalin. Water Treat., vol. 57, no. 35, pp. 16456-16465, 2016.

[13] C. Pakpum and N. Pussadee, "Design of Experiments for (100) Si Vertical Wall Wet Etching Using Sonicated NaOH Solution,” Appl. Mech. Mater., vol. 804, no. October 2015, pp. 12-15, 2015.

[14] M. F. A. Muttalib, R. Y. Chen, S. J. Pearce, and M. D. B. Charlton, “ Optimization of reactive-ion etching (RIE) parameters for fabrication of tantalum pentoxide (Ta 2 O 5 ) waveguide using Taguchi method, " EPJ Web Conf., vol. 162, p. 01003, 2017.

[15] K. A. Mustafa, J. Yunas, A. A. Hamzah, and B. Y. Majlis, "Application of BOE and KOH+IPA for fabrication of smooth nanopore membrane surface for artificial kidney," Proc. 2017 IEEE Reg. Symp. Micro Nanoelectron. RSM 2017, pp. 18-21, 2017.

[16] N. Soin and B. Y. Majlis, "Development of perfect silicon corrugated diaphragm using anisotropic etching," Microelectron. Eng., vol. 83, no. 4, pp. 1438-1441, 2006.

[17] I. Zubel, K. Rola, and M. Kramkowska, "The effect of isopropyl alcohol concentration on the etching process of Sisubstrates in KOH solutions," Sensors Actuators A Phys., vol. 171, no. 2, pp. 436-445, Nov. 2011.

[18] N. Yusof, N. Soin, and A. C. W. Noorakma, "Simulation study of convex corner undercutting in KOH and TMAH for a MEMS piezoresistive accelerometer," vol. 78,no 6, pp. 69-76, 2015.

[19] N. Yusof, A. C. W. Noorakma, and N. Soin, "Corner compensation mask design on (MEMS) accelerometer structure,” 2014 IEEE Int. Conf. Semicond. Electron., pp. 248-251, Aug. 2014.

[20] N. Burham, A. A. Hamzah, J. Yunas, and B. Y. Majlis, "Electrochemically etched nanoporous silicon membrane for separation of biological molecules in mixture," J. Micromechanics Microengineering, vol. 27, no. 7, pp.1-9, 2017.

[21] U. Abidin, B. Y. Majlis, and J. Yunas, "Fabrication of pyramidal cavity structure with micron-sized tip using anisotropic KOH etching of silicon (100)," J. Teknol., vol. 74, no. 10, pp. 137-148, 2015.

[22] S. K. Behera, H. Meena, S. Chakraborty, and B. C. Meikap, "Application of response surface methodology (RSM) for optimization of leaching parameters for ash reduction from low-grade coal," Int. J. Min. Sci. Technol., vol.28, no.4 pp. 621-629, 2018.

[23] R. Izamshah, M. Akmal, M. A. Ali, and M. S. Kasim, "Performance evaluation of rotary mechanism characteristics by response surface methodology in cylindrical wire electrical discharge turning," Adv. Mater. Process. Technol., vol. 4, no.2, pp. 281-295, 2017.

[24] A. P. Tiwary, B. B. Pradhan, and B. Bhattacharyya, "Study on the influence of micro-EDM process parameters during machining of Ti-6Al-4V superalloy," Int. J. Adv. Manuf. Technol., vol. 76, no. 1-4, pp. 151-160, 2014.

[25] M. H. Cetin, B. Ozcelik, E. Kuram, and E. Demirbas, "Evaluation of vegetable based cutting fluids with extreme pressure and cutting parameters in turning of AISI 304L by Taguchi method," J. Clean. Prod., vol. 19, no. 17-18, pp. 2049-2056, 2011. 


\section{BIOGRAPHIES OF AUTHORS}

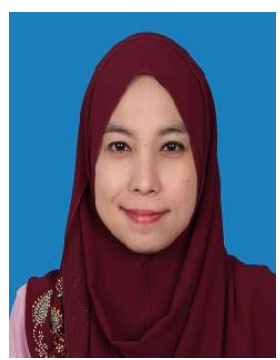

Norliana Yusof received the B.Eng (Hons.) from Universiti Teknologi Malaysia and the M.Eng degree from University of Malaya, Malaysia, in 2004 and 2010, respectively. She is currently a $\mathrm{PhD}$ student in Institute of Microengineering and Nanoelectronics (IMEN), Universiti Kebangsaan Malaysia, 43600 Bangi, Selangor, Malaysia. Her current research interests include Micro-Electro-Mechanical Systems (MEMS) devices.

Email:P86120@siswa.ukm.edu.my

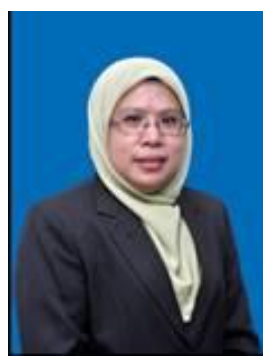

Badariah Bais received both her B.Sc. degree in Electronics Engineering and M.Sc. degree in Microelectronics from the Worcester Polytechnic Institute, Worcester, MA, U.S.A in 1990 and 1992, respectively and $\mathrm{PhD}$ from the Institute of Microengineering and Nanoelectronics (IMEN) at Universiti Kebangsaan Malaysia in 2007. Since 1997, she has been serving at the Department of Electrical, Electronics and Systems Engineering now known as Centre of Advanced Electronic and Communication Engineering (PAKET) at Universiti Kebangsaan Malaysia as an academic staff. She is currently an Associate Professor in the Centre. Her research interests include MEMS sensors and microfabrication. She is a senior member of the Institute of Electrical and Electronics Engineer (IEEE), Electron Devices Society (EDS).

Email: badariah@ukm.edu.my

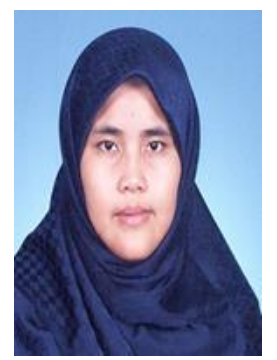

Norhayati Soin received the B.Eng (Hons.) and M.Sc degrees from Liverpool John Moores University, Liverpool, U.K., in 1991 and 1998, respectively, and the P.hD degree from the National University of Malaysia, Bangi, Malaysia in 2006. She is currently a Professor with the University of Malaya, Kuala Lumpur, Malaysia. Her current research interests include MicroElectro-MechanicalSystems (MEMS) devices, Microelectronics, IC Design and Semiconductor Device Modeling. Email:norhayatisoin@um.edu.my

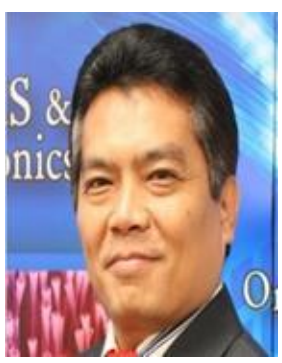

Jumril Yunas received his Ph.D. in MEMS and Nanoelectronics from Universiti Kebangsaan Malaysia (UKM) in 2008, Bachelor and Master in Electrical Engineering from RWTH Aachen University (Germany). He is currently an Associate Professor in Institute of Microengineering and Nanoelectronics (IMEN), UKM, Malaysia. His current research interests include MEMS/NEMS devices and technology, Lab on Chip, Micro-sensors and microactuators, RF devices, power electronics and optoelectronic devices. Email: jumrilyunas@ukm.edu.my

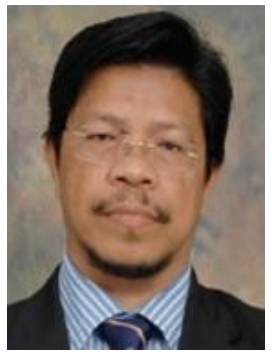

Burhanuddin Yeop Majlis received his Ph.D. in microelectronics from University of Durham, United Kingdom in 1988, MSc in microelectronics from University of Wales, UK in 1980 and BSc (Hons.) in Physics from UKM in 1979. He is a senior member of the Institution of Electrical and Electronics Engineer (IEEE) and the Chairman of IEEE Electron Devices Malaysia Chapter from 1994 to 2006. His current interest are design and fabrication of MEMS sensor, RFMEMS, BiOMEMS and microenergy. He has published four text books in electronics and one book on Integrated Circuits Fabrication Technology for undergraduate courses and more than 400 academic research papers. Now he is the founder director of Institute of Microengineering and Nanoelectronics (IMEN). Email:burhan@ukm.edu.my 